\title{
Graphene-Tapered ZnO Nanorods Array as a Flexible Antireflection Layer
}

\author{
Taeseup Song \\ School of Materials Science and Engineering, Yeungnam University, Gyeongsan 712-749, Republic of Korea \\ Correspondence should be addressed to Taeseup Song; tsong@yu.ac.kr
}

Received 21 May 2015; Revised 9 July 2015; Accepted 13 July 2015

Academic Editor: Xiaogang Han

Copyright (C) 2015 Taeseup Song. This is an open access article distributed under the Creative Commons Attribution License, which permits unrestricted use, distribution, and reproduction in any medium, provided the original work is properly cited.

\begin{abstract}
Flexible solar cells have drawn a great deal of attention due to their various advantages including deformable and wearable characteristics. In the solar cells, the antireflection layer plays an important role in the improvement in the conversion efficiency by increasing the light transmission and suppressing the Fresnel refraction. For the successful implantation of the antireflection layer into the flexible solar cells, the flexible mechanical property of the antireflection layer is also necessary. However, the study on flexible antireflection layer for the flexible solar cells or optoelectronics is still lacking. In this study, we report the graphene-tapered $\mathrm{ZnO}$ nanorods array as a flexible antireflection layer for the application in flexible solar cells. Flexible two-dimensional graphene sheet and the tapered morphology of $\mathrm{ZnO}$ nanorods enable conformal coverage on the flexible substrate with curved surface and significant improvements in antireflection properties, respectively.
\end{abstract}

\section{Introduction}

Flexible solar cells have drawn a great deal of attention in recent years due to their various advantages including lightweight, deformable, and wearable characteristics $[1,2]$. Significant advances in both the performance and the processability have been achieved via engineering in active materials [3-5] and cell structures [6-8]. Antireflection layer is considered as an indispensable component in solar cells as it plays an important role in the improvement in the conversion efficiency of solar cells by increasing the light transmission and suppressing the Fresnel refraction of a material over a broad range of wavelengths [9-11]. Although many studies on flexible solar cells were carried out, the study on antireflection layer for the flexible solar cells or optoelectronics is still lacking. Recently, the transparent paper-based antireflection coating method was reported to improve the solar cells efficiency, which shows the possibility of utilizing it in the flexible solar cells [12-14]. However, further study should be carried out for its practical use.

Among various antireflection materials, $\mathrm{ZnO}$, which is a semiconducting material with a wide-direct band gap of $3.37 \mathrm{eV}$, has been considered as a promising candidate owing to its high transmittance and appropriate refractive index $(n=2$, at a wave length of $600 \mathrm{~nm})$ associated with that of air $(n=1)$. In particular, $\mathrm{ZnO}$ nanorods array, with vertically aligned one-dimensional geometry, shows promise due to ability to form textured coating via anisotropic growth and its significant surface to volume ratio [15-17]. Chung et al. demonstrated that $\mathrm{ZnO}$ nanorods array enables the significant improvement in the light trapping and the reduction in Frensel reflection resulting from the grading in the reflection index by avoiding the abrupt transition at the air/solar cells interface [18]. Furthermore, antireflection property of $\mathrm{ZnO}$ nanorods array could be further improved by engineering the morphology at the tip. Lee et al. demonstrated that tapering at the tip of $\mathrm{ZnO}$ nanorod leads to significant improvement in antireflection property by the elimination of interference fringes through roughening of the air- $\mathrm{ZnO}$ interface [19]. Graphene, a single-layered two-dimensional carbon sheet with a hexagonal packed lattice structure, has also received significant attention for the various applications including an active material for the electronic devices, a sacrificial template for the synthesis of 2D materials and due to its unique physicochemical properties. In particular, excellent mechanical properties of graphene sheet, the breaking 


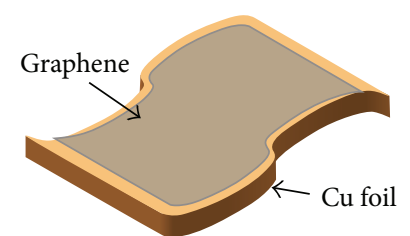

Synthesis of the graphene sheet on the $\mathrm{Cu}$ foil

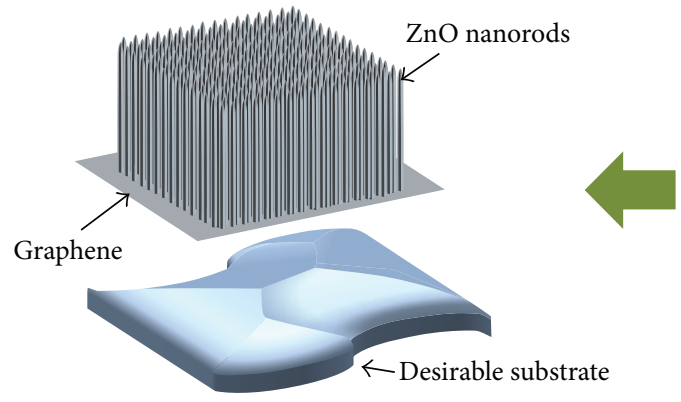

Detach graphene- $\mathrm{ZnO}$ nanorods array from the glass and transfer it to a desirable substrate
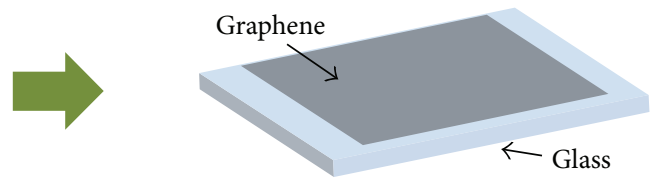

Transfer of the graphene sheet from the $\mathrm{Cu}$ foil to the glass
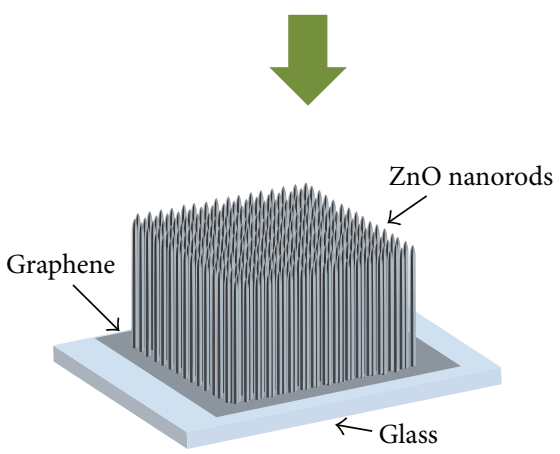

Synthesis of the $\mathrm{ZnO}$ nanorods array on the graphene sheet

SCHEme 1: Schematic illustration of the fabrication process of the flexible graphene- $\mathrm{ZnO}$ nanorods array.

strength of $42 \mathrm{~N} \mathrm{~m}^{-1}$ and Young's modulus of 1.0 TPa, enables its practical use as a flexible and transparent electrode for various flexible devices [20]. Wang et al. demonstrated that the device thickness plays an important role on conformal contact between the flexible device and the desirable substrate [21]. Graphene could be the promising substrate for the fabrication of flexible antireflection layer based on $\mathrm{ZnO}$ nanorods array due to above mentioned advantages.

In this study, we report graphene-tapered $\mathrm{ZnO}$ nanorods array as a flexible antireflection layer for the flexible solar cells application. Flexible two-dimensional graphene sheet enables conformal coverage on the curved and bumpy surface even under highly bended condition. Our designed graphenetapered $\mathrm{ZnO}$ nanorods array on the polydimethylsiloxane (PDMS) substrate exhibited robust antireflection properties after several bending experiences. We achieve robust and excellent antireflection properties on the bumpy surface by combining the advantages of the flexibility from the graphene sheet and significantly improved antireflection properties from tapered $\mathrm{ZnO}$ nanorods array.

\section{Materials and Methods}

The graphene sheet was synthesized on $25 \mu \mathrm{m}$ thick copper foil by chemical vapor deposition method at $1,000^{\circ} \mathrm{C}$ under a $30-50 \mathrm{sccm}$ of $\mathrm{CH}_{4}$ for $30 \mathrm{~min}$. The synthesis of graphene sheet is described elsewhere in detail [22]. $\mathrm{ZnO}$ thin film as a seed layer for the synthesis of $\mathrm{ZnO}$ nanorods was deposited on the graphene using radio frequency magnetron sputtering. The typical $\mathrm{ZnO}$ nanorods were synthesized using a hydrothermal method. $\mathrm{ZnO}$ seed layer coated substrate was immersed into aqueous solution containing $0.025 \mathrm{M}$ zinc nitrate hexahydrate (Sigma-Aldrich) and $0.025 \mathrm{M}$ hexamethylenetetramine (Sigma-Aldrich) at $80^{\circ} \mathrm{C}$. 1,3-Diaminopropane (Aldrich, $190 \mathrm{mM}$ ) was added into the precursor solution to synthesize tapered $\mathrm{ZnO}$ nanorods. The typical and tapered $\mathrm{ZnO}$ nanorods grown on the graphene substrate were washed by deionized water. Detailed synthesis method for $\mathrm{ZnO}$ nanorods array is described elsewhere [19, 23]. The polydimethylsiloxane (PDMS, Sylgard 184, Dow Corning), with base to cross-linking agent with a mass ratio of $10: 1$, was employed as a flexible substrate to evaluate the optical properties of graphene- $\mathrm{ZnO}$ nanorods array as an antireflection layer on the flexible substrate. As synthesized samples were characterized using a field emission scanning electron microscope (FE-SEM, S-4700, Hitachi, Hitachi City, Japan), X-ray diffraction (PANalytical X'Pert, Almelo, Netherlands), and optical microscope (Olympus U-TV 0.5XC2, Japan). Optical properties were evaluated using Varian Carry 5000 model UV-vis-NIR spectrophotometer.

\section{Results and Discussion}

Scheme 1 demonstrates the fabrication process of graphene$\mathrm{ZnO}$ nanorods array. Graphene sheet is synthesized on the $\mathrm{Cu}$ foil using chemical vapor deposition method and then carefully transferred to the slide glass by selective etching of metal foil. Typical $\mathrm{ZnO}$ nanorods and tapered $\mathrm{ZnO}$ nanorods arrays were synthesized on the graphene sheet using hydrothermal method. (Please see the experimental part for detailed information). The graphene- $\mathrm{ZnO}$ nanorods 


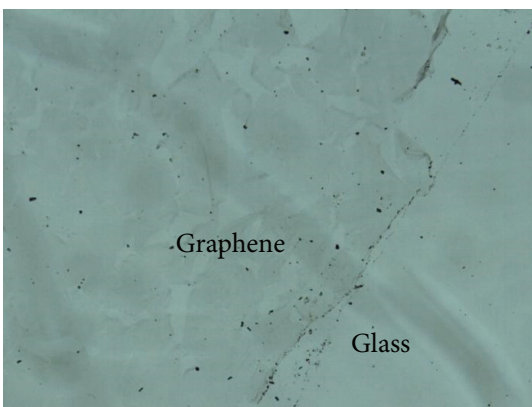

(a)

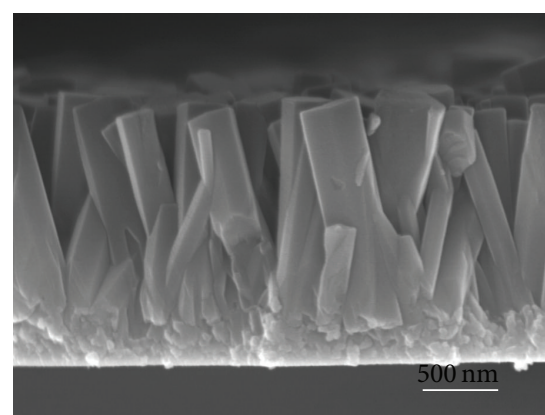

(d)

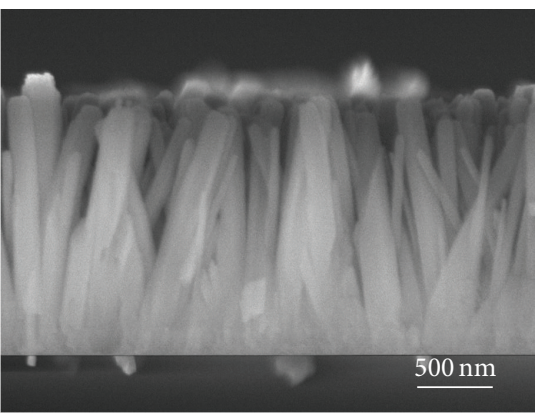

(g)

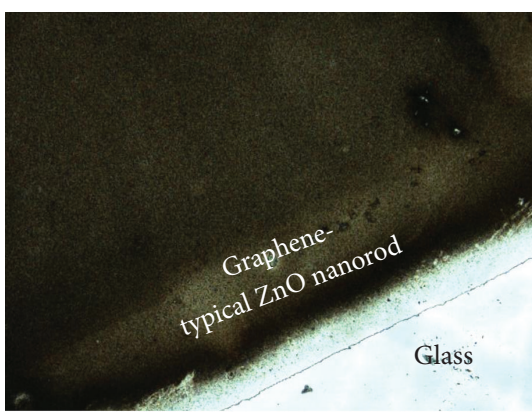

(b)

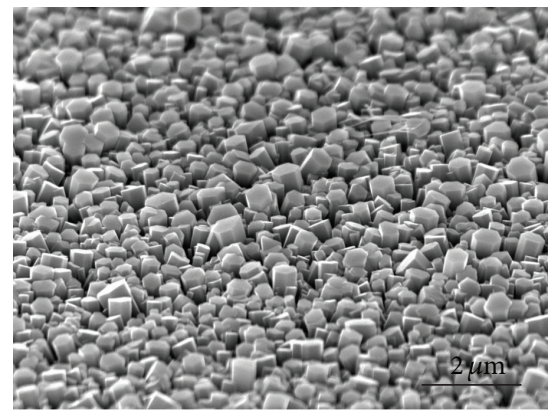

(e)

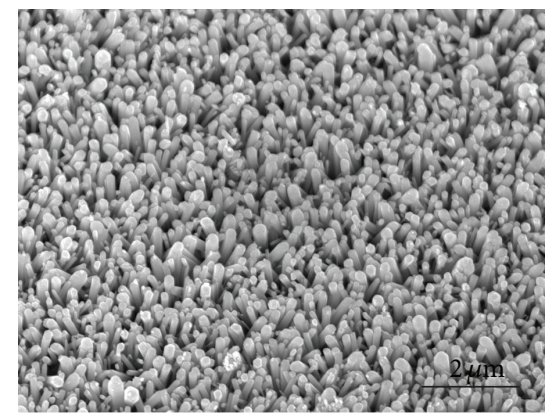

(h)

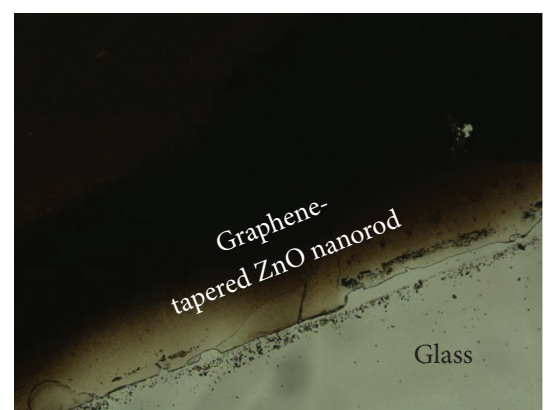

(c)

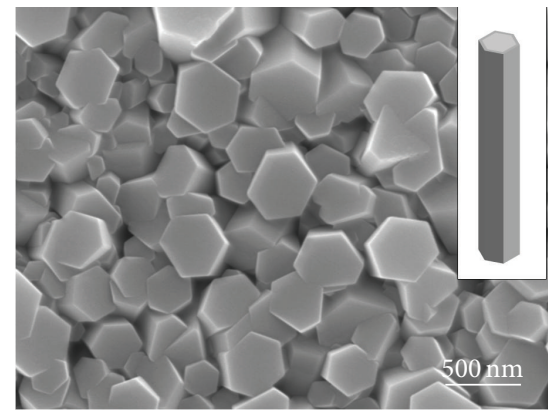

(f)

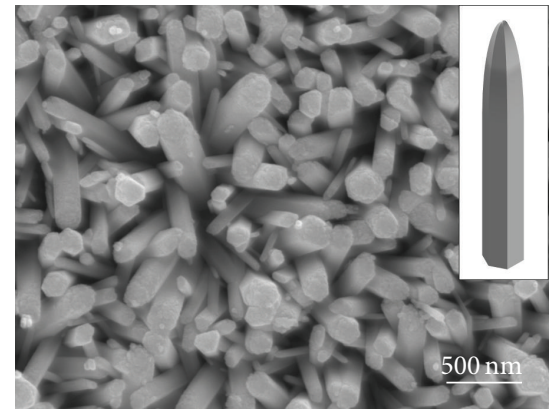

(i)

FIGURE 1: Photographs and SEM images of graphene (a), graphene-typical ZnO nanorods array ((b), (d)-(f)), and graphene-tapered ZnO nanorods array ((c), (g)-(i)). Cross-sectional SEM images ((d) and (g)), low magnification tilted view ((e) and (h)), and high magnification tilted view $((\mathrm{f})$ and $(\mathrm{i}))$.

array was detached from the slide glass and then transferred to the desirable surface of the devices.

Figure 1 presents the photographs and scanning electron microscopy (SEM) images of the graphene sheet and $\mathrm{ZnO}$ nanorods arrays on the graphene sheet. As shown in Figure 1(a), graphene sheet was successfully transferred to the slide glass from the $\mathrm{Cu}$ foil. As shown in crosssectional SEM images (Figures $1(\mathrm{~d})$ and $1(\mathrm{~g})$ ), the length of typical $\mathrm{ZnO}$ nanorods and tapered $\mathrm{ZnO}$ nanorods grown on the graphene sheet is identical $(\sim 2 \mu \mathrm{m})$. The tilted SEM images show the vertically aligned geometry of both $\mathrm{ZnO}$ nanorods arrays. The flat top and tapered shape at the tip are clearly observed in typical $\mathrm{ZnO}$ nanorods and tapered $\mathrm{ZnO}$ nanorods, respectively, in high magnification SEM images. The insets in Figures 1(f) and 1(i) present schematic illustration of the morphologies of typical $\mathrm{ZnO}$ and tapered $\mathrm{ZnO}$ nanorods. The densities of both $\mathrm{ZnO}$ nanorods arrays are about $9 \times 10^{8} / \mathrm{cm}^{2}$. Typical $\mathrm{ZnO}$ nanorod and tapered $\mathrm{ZnO}$ nanorod have the diameters of $300 \mathrm{~nm}$ and $50 \mathrm{~nm}$ at the tip, respectively.

X-ray diffraction (XRD) analysis was carried out to study the crystallinity and orientations of typical $\mathrm{ZnO}$ nanorods and tapered $\mathrm{ZnO}$ nanorods arrays on the graphene sheet. In Figure 2(a) no noticeable difference between both $\mathrm{ZnO}$ nanorod arrays was observed in XRD result. Both $\mathrm{ZnO}$ nanorods arrays exhibit diffraction peaks at $2 \theta=34.4^{\circ}$ and $63.4^{\circ}$, corresponding to the (002) and (103) planes of the hexagonal wurtzite $\mathrm{ZnO}$ phase. A strong peak at $2 \theta$ $=34.4^{\circ}$ indicates the preferred growth direction of $\mathrm{ZnO}$ phase with (002). Raman spectroscopy was employed to further investigate the structural characterizations of graphene sheet, graphene-typical $\mathrm{ZnO}$ nanorods array and graphenetapered $\mathrm{ZnO}$ nanorods array. In Figure 2(b) the graphene sheet presents the typical Raman spectrum of one layer 


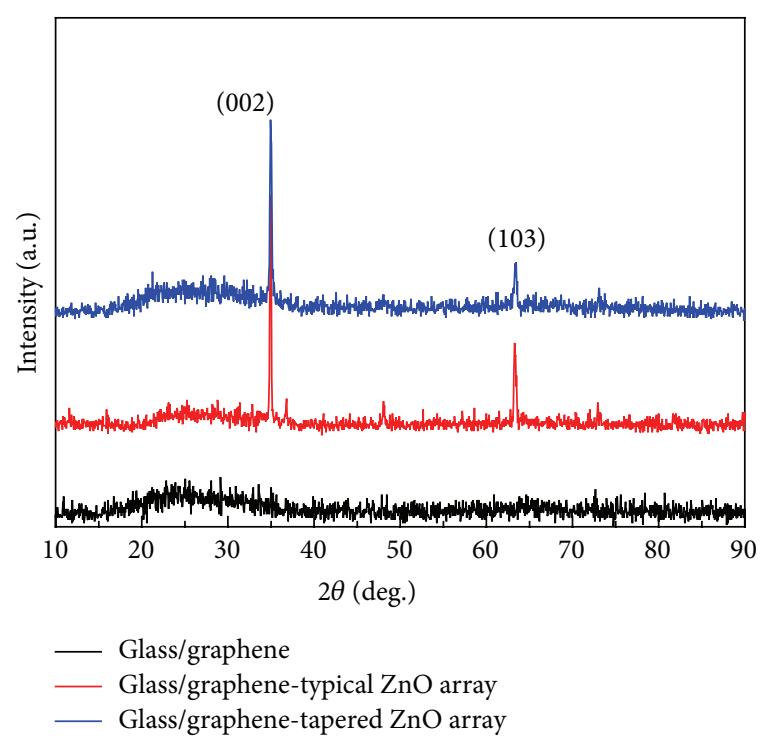

(a)

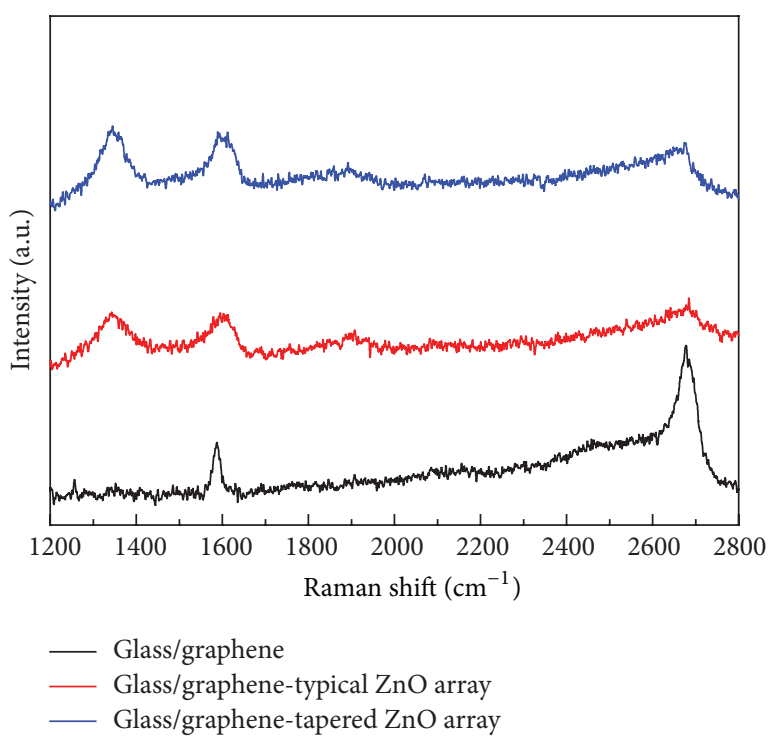

(b)

FIGURE 2: XRD (a) and Raman (b) data for graphene, graphene-typical $\mathrm{ZnO}$ nanorods array, and graphene-tapered $\mathrm{ZnO}$ nanorods array.

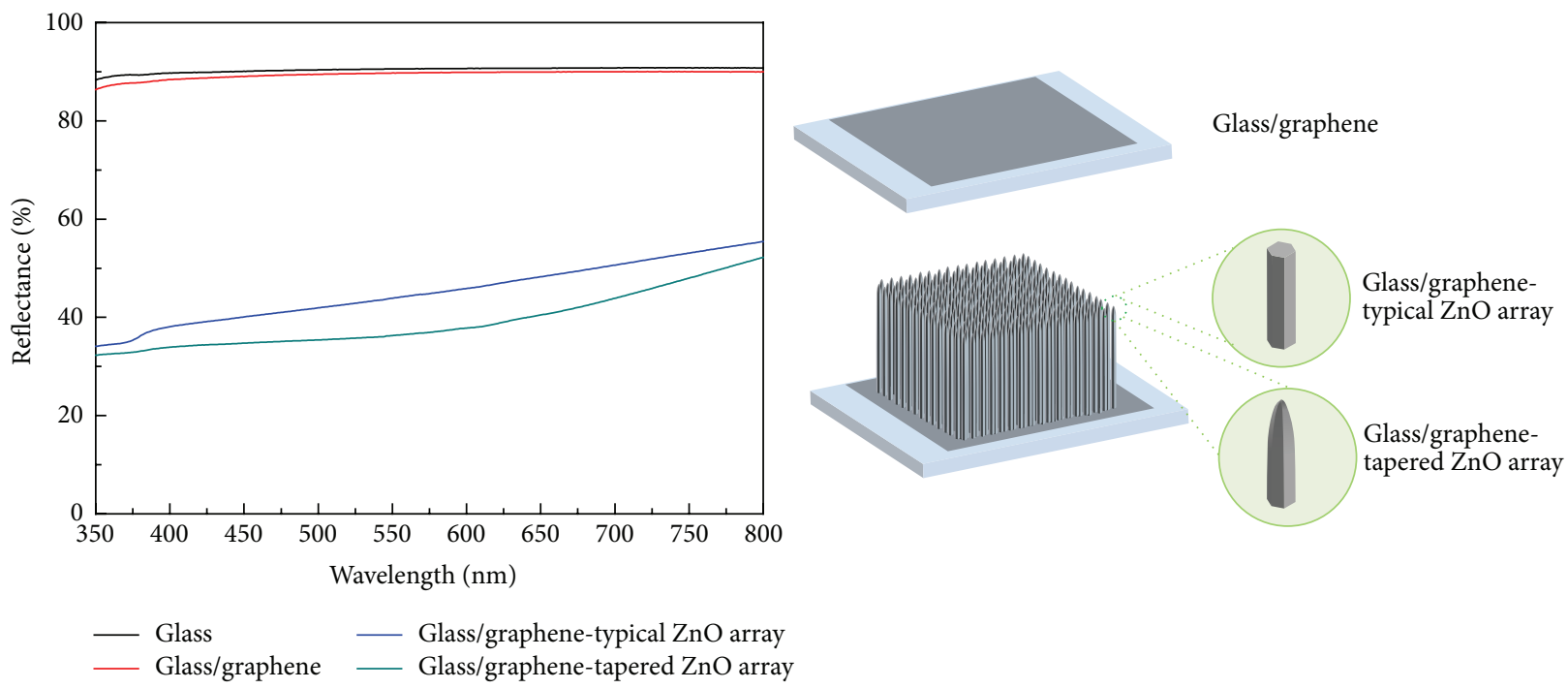

FIGURE 3: Reflectance spectra of glass/graphene, glass/graphene-typical $\mathrm{ZnO}$ array, and glass/graphene-tapered $\mathrm{ZnO}$ array.

graphene [22]. The new peak at $1345 \mathrm{~cm}^{-1}$ assigned to D band was generated after $\mathrm{ZnO}$ nanorods growth regardless of their shape at the tip, which indicates a reduction of the average size of the $\mathrm{sp}^{2}$ domains and the generation of defects after $\mathrm{ZnO}$ nanorods growth [24-26]. We also carefully measured the Raman spectrum of the graphene-tapered $\mathrm{ZnO}$ nanorods arrays after their transfer from the glass to the flat and rough PDMS substrate. The results are exhibited in Figure S1, in Supplementary Material available online at http://dx.doi.org/10.1155/2015/925863, a noticeable difference in the spectra was not observed before/after the transfer of the graphene-tapered $\mathrm{ZnO}$ nanorods arrays, which indicates that the graphene layer was successfully transferred to the flat and rough PDMS substrate.
The reflectance spectra for graphene, graphene- $\mathrm{ZnO}$ nanorods, and graphene-tapered $\mathrm{ZnO}$ nanorods arrays on the glass were evaluated to determine their antireflection properties in the wave length range from $350 \mathrm{~nm}$ to $400 \mathrm{~nm}$ using the standard UV-vis spectrometer. In Figure 3, the reflectance of the bare glass was also measured for comparison. Graphene sheet does not provide any antireflection property on the glass. However, both graphene- $\mathrm{ZnO}$ nanorods and graphene-tapered $\mathrm{ZnO}$ nanorods arrays coated glass exhibited significantly low reflectance over a wide range of wavelengths compared to graphene coated glass, which results from the textured coating via anisotropic growth and appropriate refractive index $[27,28]$. As expected, the tapered $\mathrm{ZnO}$ nanorods array coated glass shows further improved 

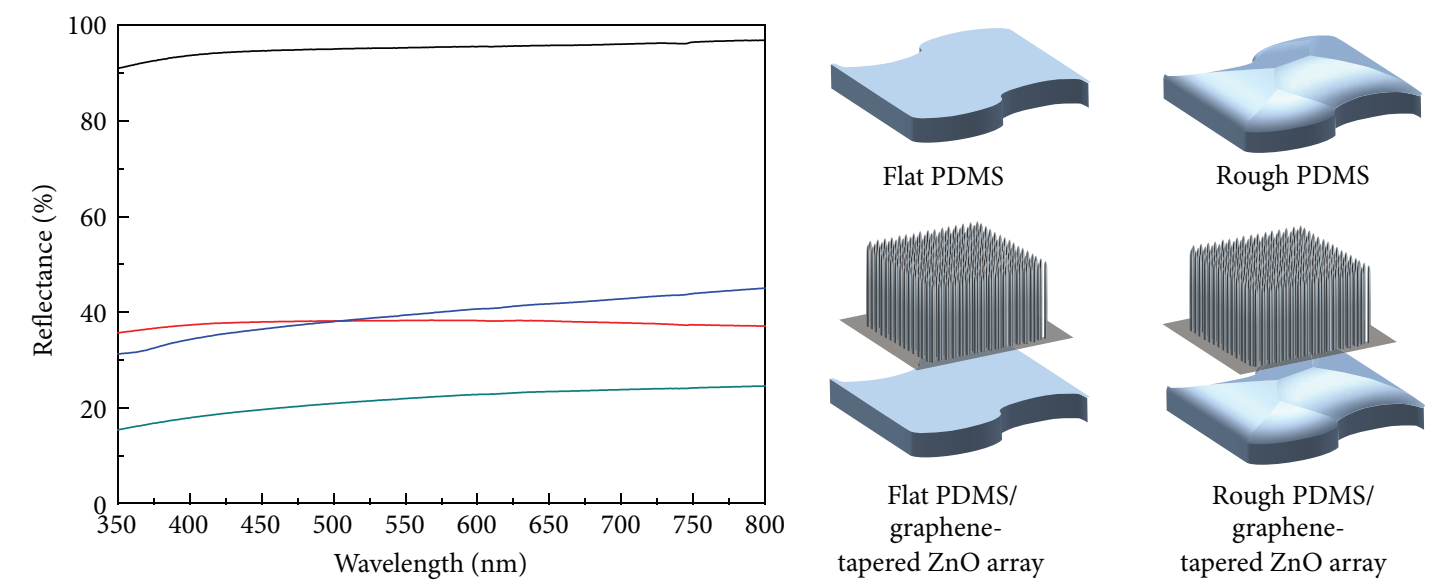

$\begin{array}{ll}\text { Flat PDMS } & \text { Flat PDMS/graphene-tapered } \mathrm{ZnO} \text { array } \\ \text { Rough PDMS — Rough PDMS/graphene-tapered } \mathrm{ZnO} \text { array }\end{array}$

FIGURE 4: Reflectance spectra of flat PDMS, rough PDMS, flat PDMS/graphene-tapered ZnO array, and rough PDMS/graphene-tapered ZnO array.

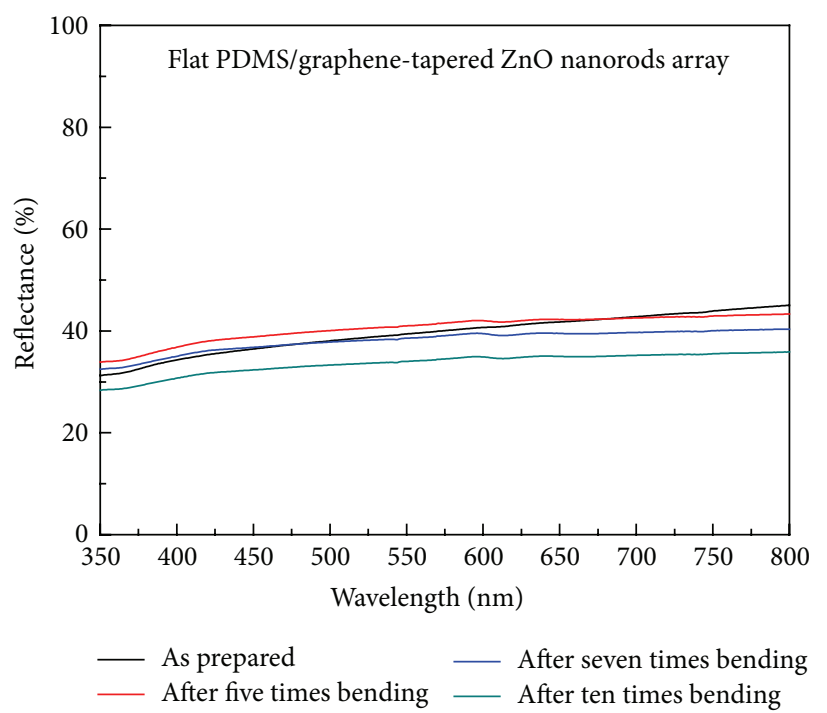

(a)

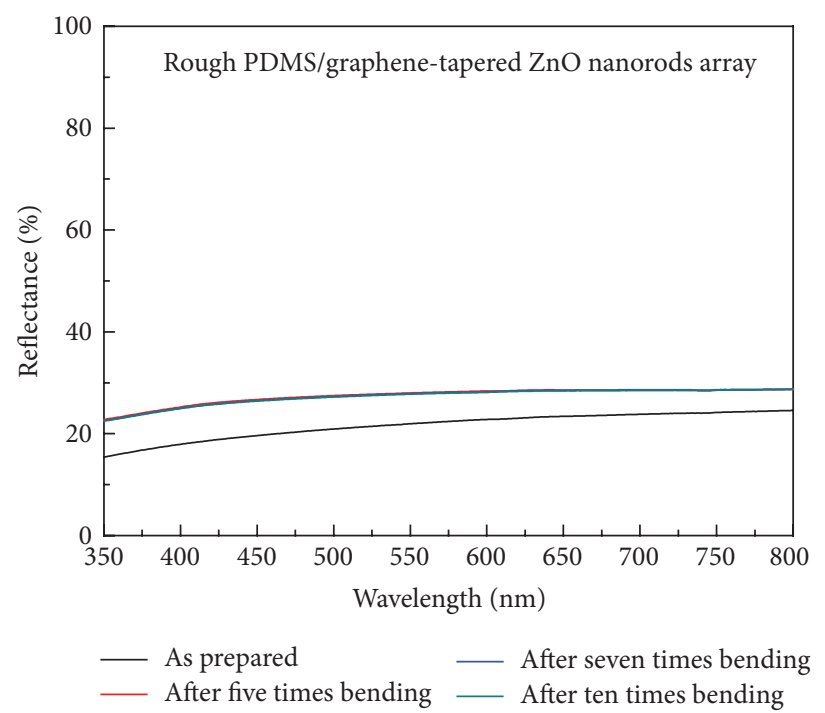

(b)

FIGURE 5: Reflectance spectra of flat (a) and rough (b) PDMS/graphene-tapered $\mathrm{ZnO}$ nanorods array as a function of the number of times being bended.

antireflection property, which is attributed to the elimination of interference fringes through roughening of the air- $\mathrm{ZnO}$ interface [19].

In order to study the antireflection properties of the graphene-tapered $\mathrm{ZnO}$ nanorods array on the flexible substrate with rough surface, two types of PDMS with flat surface and bumpy surface were prepared as a substrate for this study (Figure 4). The PDMS with rough surface exhibits much reduced reflectance compared to that of flat PDMS due to texturing effect. While the graphene-tapered $\mathrm{ZnO}$ nanorods array coated flat PDMS substrate presents comparable antireflection property with that of PDMS with rough surface, the graphene-tapered $\mathrm{ZnO}$ nanorods array coated PDMS with rough surface has the lowest reflectance, which indicates that the graphene-tapered $\mathrm{ZnO}$ nanorods array was conformably transferred to the flexible substrate with the rough surface. The mechanical properties of the PDMS/graphene-tapered $\mathrm{ZnO}$ nanorods array were evaluated as a function of the number of times being bended (Figure 5). Both the flat and rough PDMS/graphene-tapered $\mathrm{ZnO}$ nanorods array exhibited robust antireflection properties even after several bending experiences without the degradation of its mechanical properties.

\section{Conclusion}

In this study, we explored the antireflection properties of graphene- $\mathrm{ZnO}$ nanorods and graphene-tapered $\mathrm{ZnO}$ 
nanorods arrays for the application in flexible solar cells. The graphene-tapered $\mathrm{ZnO}$ nanorods array shows excellent antireflection performance compared to that of the graphenetypical $\mathrm{ZnO}$ nanorods array. Furthermore, the graphenetapered $\mathrm{ZnO}$ nanorods array is successfully transferred to the flexible substrate with the rough surface without degradation in mechanical and optical properties. Our design strategy for flexible antireflection layer could be extended to other optoelectronics.

\section{Conflict of Interests}

The author declares that there is no conflict of interests regarding the publication of this paper.

\section{Acknowledgment}

This work was supported by the 2015 Yeungnam University research grant (215A580031).

\section{References}

[1] V. Galstyan, A. Vomiero, I. Concina et al., "Vertically aligned $\mathrm{TiO}_{2}$ nanotubes on plastic substrates for flexible solar cells," Small, vol. 7, no. 17, pp. 2437-2442, 2011.

[2] Z. Y. Fan, H. Razavi, J.-W. Do et al., "Three-dimensional nanopillar-array photovoltaics on low-cost and flexible substrates," Nature Materials, vol. 8, no. 8, pp. 648-653, 2009.

[3] Z. D. Li, Y. Zhou, C. X. Bao et al., "Vertically building $\mathrm{Zn}_{2} \mathrm{SnO}_{4}$ nanowire arrays on stainless steel mesh toward fabrication of large-area, flexible dye-sensitized solar cells," Nanoscale, vol. 4, no. 11, pp. 3490-3494, 2012.

[4] P. Docampo, J. M. Ball, M. Darwich, G. E. Eperon, and H. J. Snaith, "Efficient organometal trihalide perovskite planarheterojunction solar cells on flexible polymer substrates," Nature Communications, vol. 4, article 2761, 2013.

[5] S.-I. Na, S.-S. Kim, J. Jo, and D.-Y. Kim, "Efficient and flexible ITO-free organic solar cells using highly conductive polymer anodes," Advanced Materials, vol. 20, no. 21, pp. 4061-4067, 2008.

[6] L. Hu, H. S. Kim, J.-Y. Lee, P. Peumans, and Y. Cui, "Scalable coating and properties of transparent, flexible, silver nanowire electrodes," ACS Nano, vol. 4, no. 5, pp. 2955-2963, 2010.

[7] Z. K. Liu, J. H. Li, and F. Yan, "Package-free flexible organic solar cells with graphene top electrodes," Advanced Materials, vol. 25, no. 31, pp. 4296-4301, 2013.

[8] C. Lungenschmied, G. Dennler, H. Neugebauer et al., "Flexible, long-lived, large-area, organic solar cells," Solar Energy Materials and Solar Cells, vol. 91, no. 5, pp. 379-384, 2007.

[9] C.-J. Ting, F.-Y. Chang, C.-F. Chen, and C. P. Chou, "Fabrication of an antireflective polymer optical film with subwavelength structures using a roll-to-roll micro-replication process," Journal of Micromechanics and Microengineering, vol. 18, no. 7, Article ID 075001, 2008.

[10] Z. N. Adamian, A. P. Hakhoyan, V. M. Aroutiounian, R. S. Barseghian, and K. Touryan, "Investigations of solar cells with porous silicon as antireflection layer," Solar Energy Materials and Solar Cells, vol. 64, no. 4, pp. 347-351, 2000.

[11] Z. Z. Wu, J. Walish, A. Nolte, L. Zhai, R. E. Cohen, and M. F. Rubner, "Deformable antireflection coatings from polymer and nanoparticle multilayers," Advanced Materials, vol. 18, no. 20, pp. 2699-2702, 2006.

[12] D. Ha, J. Murray, Z. Q. Fang, L. B. Hu, and J. N. Munday, "Advanced broadband antireflection coatings based on cellulose microfiber paper," IEEE Journal of Photovoltaics, vol. 5, no. 2, pp. 577-583, 2015.

[13] Z. Q. Fang, H. L. Zhu, Y. B. Yuan et al., "Novel nanostructured paper with ultrahigh transparency and ultrahigh haze for solar cells," Nano Letters, vol. 14, no. 2, pp. 765-773, 2014.

[14] D. Ha, Z. Q. Fang, L. B. Hu, and J. N. Munday, "Paper-based anti-reflection coatings for photovoltaics," Advanced Energy Materials, vol. 4, no. 9, Article ID 1301804, 2014.

[15] Y.-C. Chao, C.-Y. Chen, C.-A. Lin, Y.-A. Dai, and J.-H. He, "Antireflection effect of $\mathrm{ZnO}$ nanorod arrays," Journal of Materials Chemistry, vol. 20, no. 37, pp. 8134-8138, 2010.

[16] L.-K. Yeh, K.-Y. Lai, G.-J. Lin et al., "Giant efficiency enhancement of GaAs solar cells with graded antireflection layers based on syringelike $\mathrm{ZnO}$ nanorod arrays," Advanced Energy Materials, vol. 1, no. 4, pp. 506-510, 2011.

[17] M. K. Kim, D. K. Yi, and U. Paik, "Tunable, flexible antireflection layer of $\mathrm{ZnO}$ nanowires embedded in PDMS," Langmuir, vol. 26, no. 10, pp. 7552-7554, 2010.

[18] R.-J. Chung, Z.-C. Lin, C.-A. Lin, and K.-Y. Lai, "Study of an antireflection surface constructed of controlled $\mathrm{ZnO}$ nanostructures," Thin Solid Films, vol. 570, pp. 504-509, 2014.

[19] Y.-J. Lee, D. S. Ruby, D. W. Peters, B. B. McKenzie, and J. W. $\mathrm{P}$. Hsu, " $\mathrm{ZnO}$ nanostructures as efficient antireflection layers in solar cells," Nano Letters, vol. 8, no. 5, pp. 1501-1505, 2008.

[20] X. Huang, X. Y. Qi, F. Boey, and H. Zhang, "Graphene-based composites," Chemical Society Reviews, vol. 41, no. 2, pp. 666686, 2012.

[21] S. D. Wang, M. Li, J. Wu et al., "Mechanics of epidermal electronics," Journal of Applied Mechanics, vol. 79, no. 3, Article ID 031022, 2012.

[22] X. S. Li, W. W. Cai, J. H. An et al., "Large-area synthesis of highquality and uniform graphene films on copper foils," Science, vol. 324, no. 5932, pp. 1312-1314, 2009.

[23] T. Song, J. L. Xia, J.-H. Lee et al., "Arrays of sealed silicon nanotubes as anodes for lithium ion batteries," Nano Letters, vol. 10, no. 5, pp. 1710-1716, 2010.

[24] S. Z. Liu, H. Q. Sun, A. Suvorova, and S. B. Wang, "Onepot hydrothermal synthesis of $\mathrm{ZnO}$-reduced graphene oxide composites using Zn powders for enhanced photocatalysis," Chemical Engineering Journal, vol. 229, pp. 533-539, 2013.

[25] Q.-P. Luo, X.-Y. Yu, B.-X. Lei, H.-Y. Chen, D.-B. Kuang, and C.-Y. Su, "Reduced graphene oxide-hierarchical $\mathrm{ZnO}$ hollow sphere composites with enhanced photocurrent and photocatalytic activity," The Journal of Physical Chemistry $C$, vol. 116, no. 14, pp. 8111-8117, 2012.

[26] A. Eckmann, A. Felten, A. Mishchenko et al., "Probing the nature of defects in graphene by Raman spectroscopy," Nano Letters, vol. 12, no. 8, pp. 3925-3930, 2012.

[27] X. X. Pu, J. Liu, J. S. Liang et al., "Effective CdS/ZnO nanorod arrays as antireflection coatings for light trapping in c-Si solar cells," RSC Advances, vol. 4, no. 44, pp. 23149-23154, 2014.

[28] S.-H. Baek, B.-Y. Noh, I.-K. Park, and J. H. Kim, "Fabrication and characterization of silicon wire solar cells having $\mathrm{ZnO}$ nanorod antireflection coating on Al-doped $\mathrm{ZnO}$ seed layer," Nanoscale Research Letters, vol. 7, article 29, 2012. 

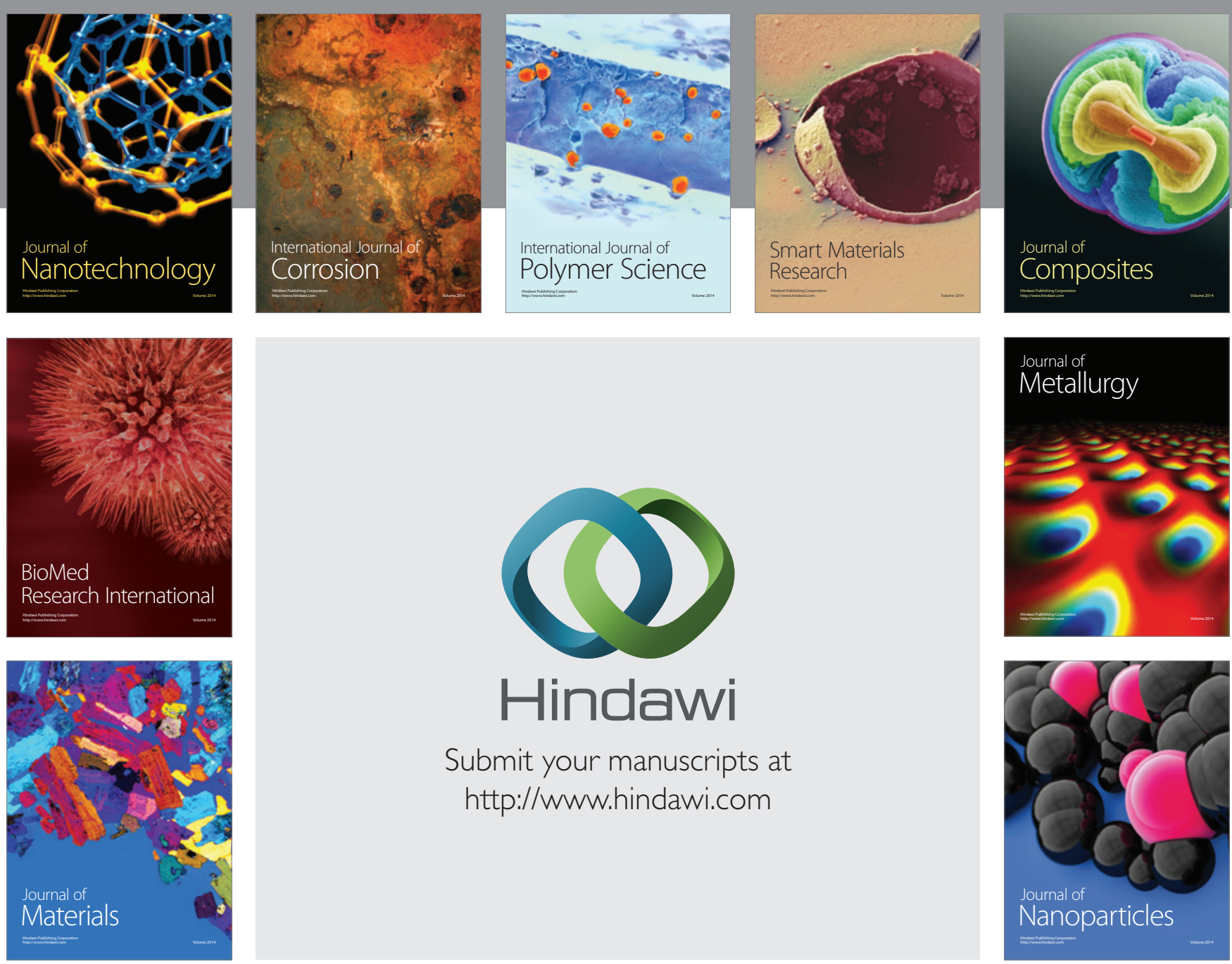

Submit your manuscripts at http://www.hindawi.com
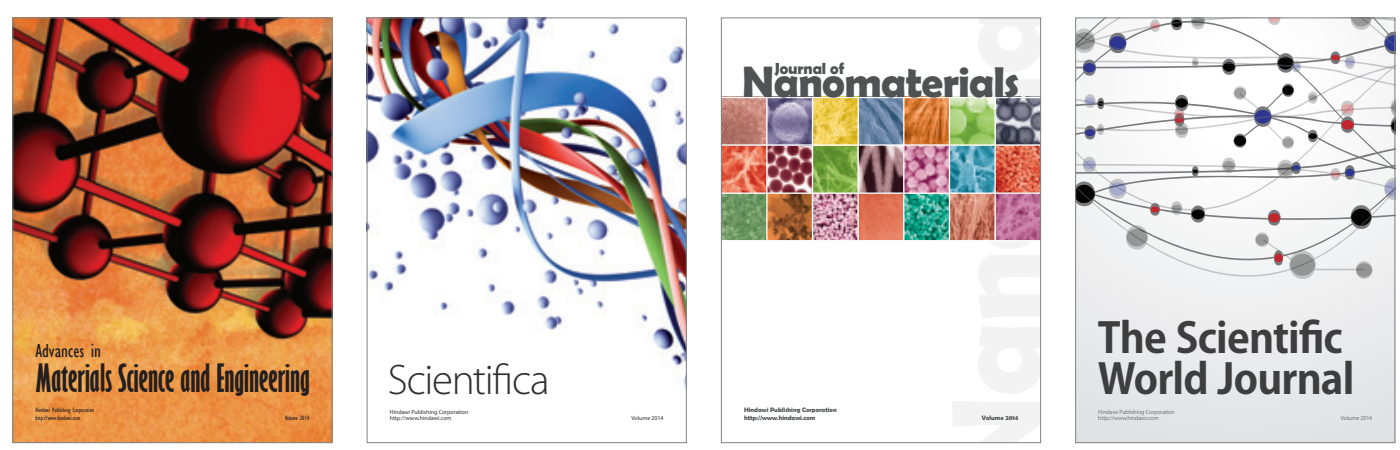

\section{The Scientific World Journal}
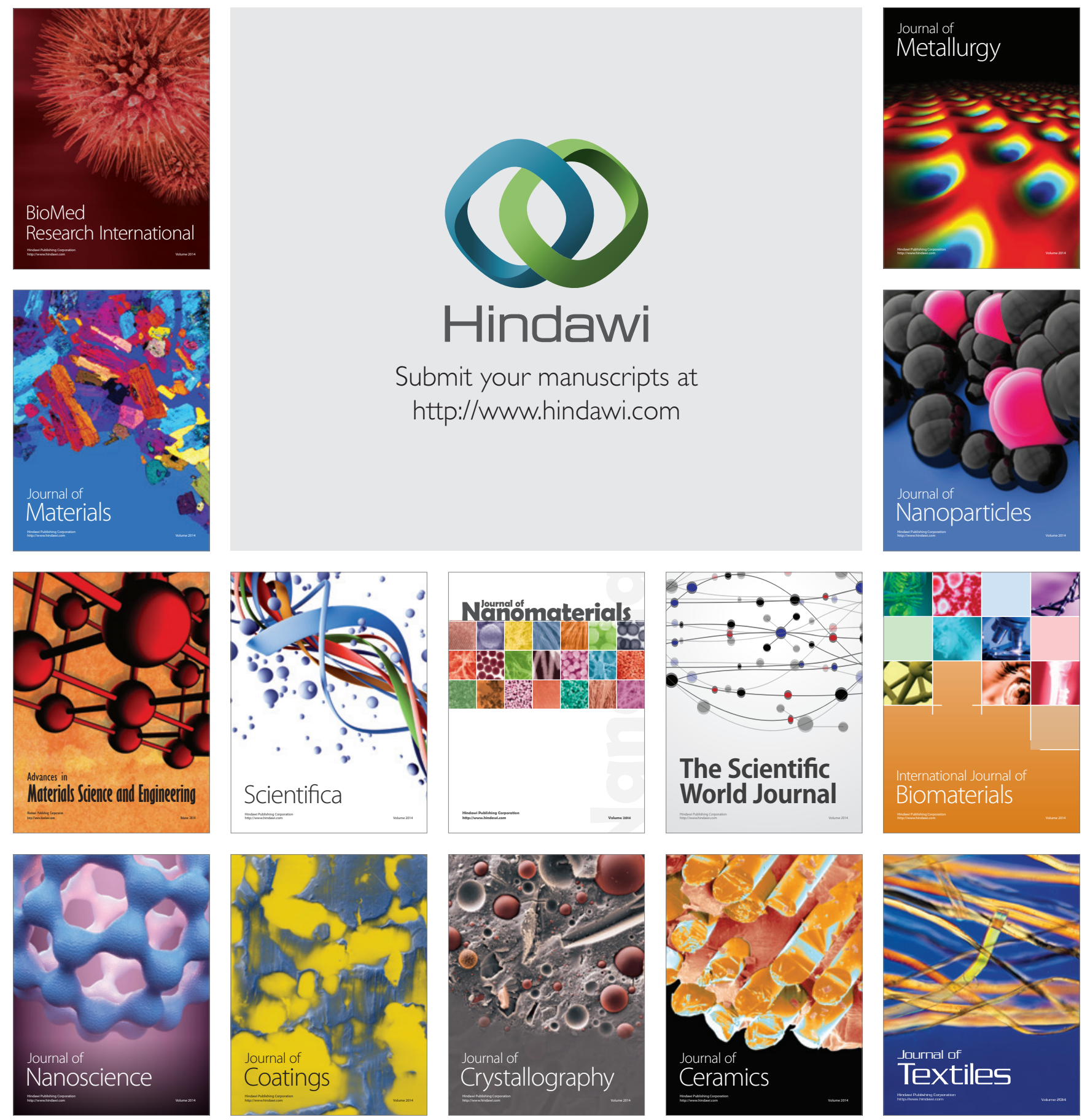